\title{
Effect of POX genotype and Lip2p overexpression on lactone production and reconsumption by Yarrowia lipolytica using castor oil as substrate
}

\author{
A. Braga ${ }^{\mathrm{a}}$, A.M. Crutz-Le Coq ${ }^{\mathrm{b}, \mathrm{c}}$, R. Dulermo $^{\mathrm{b}, \mathrm{c}}$, J.M. Nicaud ${ }^{\mathrm{b}, \mathrm{c}}$, I. Belo $^{\mathrm{a}, *}$ \\ a Centre of Biological Engineering, University of Minho, Campus de Gualtar, 4710-057 Braga, Portugal \\ b INRA, UMR1319, MICALIS, F78352 Jouy-en-Josas, France \\ c AgroParisTech, UMR Micalis, Jouy-en-Josas, France
}

\section{A R T I C L E I N F O}

\section{Article history:}

Received 19 March 2015

Received in revised form 20 April 2015

Accepted 12 May 2015

Available online 23 May 2015

Keywords:

$\beta$-Oxidation

Castor oil

$\gamma$-Decalactone production

Lipase

Yarrowia lipolytica

\begin{abstract}
A B S T R A C T
$\gamma$-Decalactone production from ricinoleic acid biotransformation by Yarrowia lipolytica has drawn the attention of many authors and, in the last years, molecular and physiological developments were made through the use of engineered strains in novel culture conditions.

The purpose of this work was to monitor the performance of modified Y. lipolytica strains in their lipid metabolism specifically at the $\beta$-oxidation pathway (MTLY40-2P strain, disrupted in the native genes POX2-5 and expressing an ectopic Aox2p-encoding gene) or at the triglyceride hydrolysis (JMY3010 strain, Lip2p overexpressed) using castor oil as substrate, in a lab-scale bioreactor. Using step-wise fedbatch cultures of MTLY40-2P strain, a $\gamma$-decalactone concentration of $7 \mathrm{~g} \mathrm{~L}^{-1}$ was reached. $\gamma$-Decalactone reconsumption was prevented and hydroxylactone production was reduced by $Y$. lipolytica MTLY40-2P strain. Moreover, substantial increase in the initial rate of aroma production was obtained with strain overexpressing LIP2 gene due to the fast hydrolysis of castor oil.
\end{abstract}

(c) 2015 Elsevier Ltd. All rights reserved.

\section{Introduction}

Biotechnological production of $\gamma$-decalactone has great interest in the food industry due to the higher acceptability by consumers in comparison with similar products obtained by chemical synthesis. This yeast is able to produce $\gamma$-decalactone by means of hydroxylated $\mathrm{C}_{18}$ fatty acid (ricinoleic acid) transformation. After $\gamma$-decalactone production pathway unravelled by Okui et al. [1] many other authors explored this topic, as is the case of EndrizziJoran et al. [2] who described the $\beta$-oxidation as the pathway for $\gamma$-decalactone production, further explored by Gatfield et al. [3], Haffner and Tressl [4] and Spinnler et al. [5]. Feron et al. [6] and Feron et al. [7] focused on the toxicity levels of this lactone, while Endrizzi-Joran [8] detailed the degradation pathway of $\gamma$-decalactone. In Yarrowia lipolytica the evidence of the involvement of $\beta$-oxidation and specifically of the acyl-CoA oxidases (Aox) in $\gamma$-decalactone production was obtained by Waché et al. [9]. The identification of the Aox encoding genes [10-12] and the characterization of theses isoenzymes $[13,14]$ paved the way to intensive metabolic engineering to better understand and control

\footnotetext{
* Corresponding author. Tel.: +35 1253604413; fax: +35 1253604429

E-mail address: ibelo@deb.uminho.pt (I. Belo).
}

$\gamma$-decalactone production [10,15-20]. Environmental conditions also revealed to be very important in aroma production $[21,22]$ and particularly the aspects of oxygen mass transfer from air into the culture medium $[23,24]$.

The yeast $Y$. lipolytica possesses a family of six acyl-CoA oxidases (Aox1 to 6 encoded by POX1 to POX6 [12]). The pathway first enzyme is generally considered as the limiting step in the catalysis [16]. The POX1 disruption resulted in an increased $\beta$-oxidation activity but a decrease on the $\gamma$-decalactone production [25]. From the POX cluster, only two of the coded proteins exhibit high activity and chain-length specificity, one being long-chain-specific, Aox2 [14] and the other short-chain-specific, Aox3 [13]. The role of the other Aox's is less evident. Aox4, Aox5 exhibited a weak activity in the whole spectrum of straight-chain acyl-CoA (from $C_{4}$ to $C_{18}$ ) and, Aox 1 and Aox6 did not exhibit any detectable activity. Latest studies to improve $\gamma$-decalactone production concerns $\beta$-oxidation pathway engineering $[9,19,25,26]$. Deleting Aox3 leads to slow $\gamma$ decalactone reconsumption [10] and others lactones production [19]. Short-chain $\beta$-oxidation was blocked by POX3 disruption and resulted in 10 -fold yield increase $[10,16]$. In addition, modification of $\beta$-oxidation fluxes at the multifunctional enzyme can trigger the switch between the production of $\gamma$-decalactone and the production of hydroxy-related lactones [21]. The yeast $Y$. lipolytica seems to have a low activity at the multifunctional enzyme level leading 
to the accumulation of three hydroxy-related lactones. The production of hydroxylactone with the Y. lipolytica $\Delta$ pox2pox3 is close to zero whereas $\gamma$-decalactone production continues [16]. These results are supported by Titorenko and coworkers [27] who demonstrated that Aox $2 \mathrm{p}$ and Aox3p enzymes are required to assemble the global acyl-CoA oxidase complex and target it into peroxisomes.

Besides metabolic engineering, strategies to improve aroma production aim into culture conditions experimentation. The effect of medium composition on $\gamma$-decalactone production has been studied by Braga et al. [28] who investigated the influence of different castor oil concentrations in batch cultures and concluded that the best substrate concentration was $30 \mathrm{~g} \mathrm{~L}^{-1}$ of castor oil, obtaining $1.8 \mathrm{~g} \mathrm{~L}^{-1}$ of $\gamma$-decalactone. The fed-batch operation is usually applied to obtain high yields and productivities, comparing to batch mode, by controlling the nutrient feeding. Gomes et al. [22] obtained a $\gamma$-decalactone productivity of $0.043 \mathrm{~g} \mathrm{~L}^{-1} \mathrm{~h}^{-1}$ for a step-wise fed-batch operation applied to $Y$. lipolytica cultures, when $30 \mathrm{gL}^{-1}$ methyl ricinoleate was fed twice to the bioreactor.

In this study we report the characterization of $\gamma$-decalactone production in a lab-scale bioreactor using two Y. lipolytica mutant strains and castor oil as substrate: one with modifications in the lipid metabolism at the $\beta$-oxidation pathway (acyl-CoA oxidases); and another with improved triglyceride hydrolysis ability due to the LIP2 overexpression.

\section{Experimental procedures}

\subsection{Microorganism, media and culture conditions}

The strains used in this work, which are listed in Table 1, were Y. lipolytica W29 (ATCC 20460) and its derived mutants with modifications in the lipid metabolism at the peroxisomal $\beta$-oxidation pathway (deleted for acyl-CoA oxidases encoding genes and POX2 overexpression) - MTLY40-2P strain or at extracellular lipase expression (LIP2 overexpression) - JMY3010 strain.

Cells were cultured for $48 \mathrm{~h}$ on YPDA medium (agar $30 \mathrm{~g} \mathrm{~L}^{-1}$, glucose $20 \mathrm{~g} \mathrm{~L}^{-1}$, peptone $20 \mathrm{~g} \mathrm{~L}^{-1}$, yeast extract $10 \mathrm{~g} \mathrm{~L}^{-1}$ ) at $27^{\circ} \mathrm{C}$. The cell colonies previously prepared were used to inoculate (cell density of $0.5 \mathrm{~g} \mathrm{~L}^{-1}$ ) a $500 \mathrm{~mL}$ baffled Erlenmeyer flask containing $200 \mathrm{~mL}$ of glucose medium (YPD medium: glucose $20 \mathrm{~g} \mathrm{~L}^{-1}$, peptone $20 \mathrm{~g} \mathrm{~L}^{-1}$, yeast extract $\left.10 \mathrm{~g} \mathrm{~L}^{-1}\right)$. Cultures were incubated at $140 \mathrm{rpm}$, at $27^{\circ} \mathrm{C}$ for $19 \mathrm{~h}$, until the total glucose consumption, and that subculture was used to inoculate $1.7 \mathrm{~L}$ of YPD medium in the bioreactor, to give an initial cell concentration of $0.5 \mathrm{~g} \mathrm{~L}^{-1}$. After the cell growth phase of $19 \mathrm{~h}$ (final cell concentration of $30 \mathrm{~g} \mathrm{~L}^{-1}$ ), the components of the biotransformation medium were added to the culture to initiate the biotransformation phase. The composition of the biotransformation medium was $6.7 \mathrm{~g} \mathrm{~L}^{-1} \mathrm{YNB}$ (yeast nitrogen base) with amino acids, $2.5 \mathrm{~g} \mathrm{~L}^{-1} \mathrm{NH}_{4} \mathrm{Cl}, 30 \mathrm{~g} \mathrm{~L}^{-1}$ or $60 \mathrm{~g} \mathrm{~L}^{-1}$ Castor oil (CO) and $3 \mathrm{~g} \mathrm{~L}^{-1}$ or $6 \mathrm{~g} \mathrm{~L}^{-1}$ Tween 80 , respectively.

Table 1

Yarrowia lipolytica strains used in this study.

\begin{tabular}{lll}
\hline Strain & Relevant genotype & Reference \\
\hline W29 (ATCC 20460) & Wild type (WT) & {$[29]$} \\
MTLY40-2P & $\Delta p o x 2 \triangle p o x 3 \Delta p o x 4$ & {$[16]$} \\
& $\Delta p o x 5+$ pPOX2 $-P O X 2$ & \\
JMY3010 & W29 derivative & Unpublished \\
& containing an & \\
& additional copy of LIP2, \\
& pTEF-LIP2 &
\end{tabular}

a The pPOX2 promoter contained a deletion that results in a decrease catabolic

\subsection{Biotransformations}

Experiments were carried out in a $3.7 \mathrm{~L}$ operating volume bioreactor (RALF PLUS SOLO, Bioengineering, Switzerland). Cellular growth occurred at $27^{\circ} \mathrm{C}$, with $500 \mathrm{rpm}$ and $3 \mathrm{~L} \mathrm{~min}^{-1}$ of aeration rate for $19 \mathrm{~h}$ until a final cell density of $30 \mathrm{~g} \mathrm{~L}^{-1}$ and total glucose consumption. After the cell growth phase biotransformations were performed at $650 \mathrm{rpm}$ with an aeration rate of $5.1 \mathrm{~L} \mathrm{~min}^{-1}$, and $\mathrm{pH} \mathrm{6}$, with two different castor oil concentrations, $30 \mathrm{~g} \mathrm{~L}^{-1}$ according with previous works $[28,31]$ and the double of this concentration $\left(60 \mathrm{~g} \mathrm{~L}^{-1}\right)$. Afterwards, a step-wise fed-batch strategy was performed, based on two additions of $60 \mathrm{~g} \mathrm{~L}^{-1}$ castor oil.

\subsection{Sampling and analytical methods}

Samples were collected through time for analysis of extracellular lipase activity, lactone quantification and cell concentration. Extracellular lipase activity was measured in the supernatant by a spectrophotometric method using $p$-nitrophenyl butyrate as substrate [32]. Lactones were extracted from $2 \mathrm{~mL}$ samples with $2 \mathrm{~mL}$ diethyl ether and the organic phase was analyzed by GC [33]. Cell concentration was estimated using a Neubauer-improved counting chamber [34].

\section{Results and discussion}

\subsection{Batch cultures}

The MTLY40-2P was proven to produce high levels of $\gamma$ decalactone [16] from methyl ricinoleate due to severely decreased short-chain fatty acid degradation and enhanced long-chain fattyacid $\beta$-oxidation through the overexpression of Aox $2 p$ [10]. To our knowledge this is the first time that a study aims to analyze the performance of this strain in CO medium. Braga et al. [28] and Braga et al. [33] pointed out the importance of extracellular lipases for the fast release of ricinoleic acid from castor oil. Thus, the JMY3010 that has an additional copy of LIP2 coding for the main extracellular lipase, highly expressed under the strong and constitutive promoter of the TEF gene (translation elongation factor 1 ), was also studied using $\mathrm{CO}$ as substrate.

Fig. 1 shows $\gamma$-decalactone production in batch cultures of the three strains with $30 \mathrm{~g} \mathrm{~L}^{-1}$ and $60 \mathrm{~g} \mathrm{~L}^{-1}$ of CO. Briefly, it was observed that for all strains the increase of $\mathrm{CO}$ concentration from $30 \mathrm{~g} \mathrm{~L}^{-1}$ to $60 \mathrm{~g} \mathrm{~L}^{-1}$ increased the aroma production. This increase was higher for WT and MTLY40-2P reaching the value of $\gamma$-decalactone of $4.1 \pm 0.4 \mathrm{~g} \mathrm{~L}^{-1}$. This value is the highest ever reported with MTLY40-2P. Groguenin et al. [16] using methyl ricinoleate as substrate with this strain in flasks assays obtained a $\gamma$-decalactone maximum concentration of $300 \mathrm{mg} \mathrm{L}^{-1}$. The two mutant strains produced higher aroma concentration for $30 \mathrm{~g} \mathrm{~L}^{-1}$ CO than the WT. The influence of different substrate concentrations on $\gamma$-dodecalactone production by permeabilized Waltomyces lipofer cells was also studied by An et al. [35]. They observed a proportional increase in the production of $\gamma$-dodecalactone with a substrate concentration increase. Nevertheless, for substrate concentrations higher than $60 \mathrm{~g} \mathrm{~L}^{-1}$ the production reached a plateau. On the other hand, Alchihab et al. [36] observed that $\gamma$-decalactone concentration obtained with the strain Rhodotorula aurantiaca was not proportional to the concentration of castor oil added.

The kinetic profile of $\gamma$-decalactone production for the WT shows a maximum of aroma production followed by a rapid aroma reconsumption, typical for this strain in batch cultures on several substrates [21-24,31,33]. The mutants contrasting profile exhibit no significant decrease at the end of the experiment, except for the MTYL40-2P with $60 \mathrm{~g} \mathrm{~L}^{-1} \mathrm{CO}$ where a $30 \%$ decrease in $\gamma$-decalactone concentration occurred. 

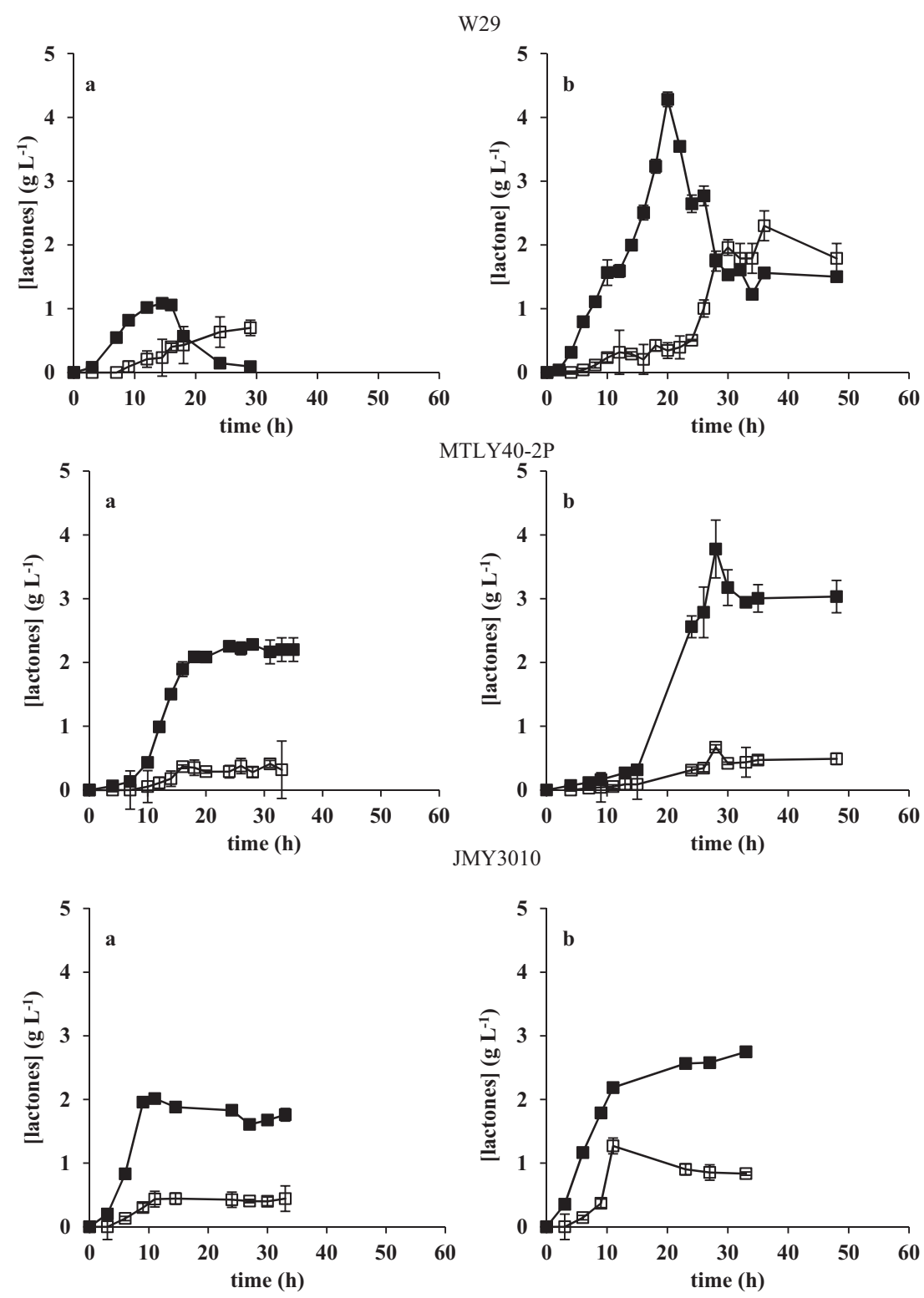

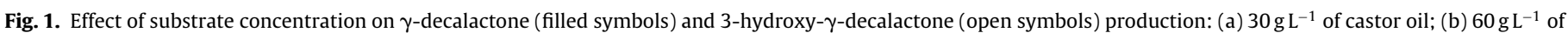
castor oil. Data are presented as mean with the standard deviation of three independent experiments.

The MTYL40-2P exhibited higher $\gamma$-decalactone production than the W29. Indeed the disruption of POX3 coding the shortchain specific enzyme (Aox3) avoided degradation of the aroma or its precursor via continuation of $\beta$-oxidation after $C_{10}$ level or lactone reconsumption. Strains lacking the short-chain Aox (Aox3) consumed more slowly $\gamma$-decalactone [10,19,37]. The slight reconsumption observed at $60 \mathrm{~g} \mathrm{~L}^{-1} \mathrm{CO}$ is probably a result of the basal transcription levels of Axo1 and Aox6. However, the lack of $\gamma$-decalactone reconsumption in JMY3010 was unexpected as this strain was not modified for its $\beta$-oxidation and possibly one of the hydrolysis products of castor oil, rapidly generated by overexpressed of LIP2, could be involved in the regulation of the $\beta$-oxidation pathway or other flux responsible for lactone reconsumption. We hypothesize that rapid release of glycerol upon CO hydrolysis could result in repression of POX, MFE1 and POT1 genes in this strain. Indeed, these genes were shown to be repressed by glucose and glycerol in a previous transcriptomic analysis (Morin and Nicaud, unpublished results). For example, POX2 and POX3 expression is about 10 -fold lower in glucose and glycerol compared to oil or fatty acid media. Even POX3 appeared to be more repressed than POX2 by glycerol than by glucose. This may explain the slowdown production after $10 \mathrm{~h}$ in JMY3010 compared to the WT and the absence of $\gamma$-decalactone reconsumption.

Since $\beta$-oxidation pathway may lead to the accumulation of other compounds derived from 4-hydroxydecanoic acid (precursor of $\gamma$-decalactone), the production of 3-hydroxy- $\gamma$-decalactone was analyzed (Fig. 1). As expected higher hydroxy-lactone concentration was achieved for strains that were not manipulated at $\beta$-oxidation level (W29 and JMY3010). Moreover, 3-hydroxy- $\gamma$ decalactone production increases as the $\mathrm{CO}$ concentration increases from $30 \mathrm{~g} \mathrm{~L}^{-1}$ to $60 \mathrm{~g} \mathrm{~L}^{-1}$ for these two strains. In this case, when more substrate is present the production of hydroxy-related lactones increases due to the substrate availability, since the pathway is not blocked after $C_{10}$. Also, for W29 3-hydroxy- $\gamma$ decalactone increases as $\gamma$-decalactone is consumed, by opposition with MTLY40-2P (POX3 disrupted gene) for which hydroxylactone production is reduced. 
Table 2

Maximum $\gamma$-decalactone and 3-hydroxy- $\gamma$-decalactone productivity in batch cultures. Data are presented as the mean with the standard deviation of three independent experiments.

\begin{tabular}{llll}
\hline Strain & {$[\mathrm{CO}]\left(\mathrm{g} \mathrm{L}^{-1}\right)$} & $\begin{array}{l}\gamma \text {-Decalactone } \\
\text { productivity } \\
\left(\mathrm{g} \mathrm{L}^{-1} \mathrm{~h}^{-1}\right)\end{array}$ & $\begin{array}{l}\text { 3-Hydroximum } \\
\text { decalactone } \\
\text { productivity }\end{array}$ \\
\hline \multirow{2}{*}{ W29 } & 30 & $0.08 \pm 0.01$ & $0.02 \pm 0.01$ \\
& 60 & $0.21 \pm 0.03$ & $0.07 \pm 0.01$ \\
MTLY40-2P & 30 & $0.08 \pm 0.01$ & $0.01 \pm 0.004$ \\
& 60 & $0.14 \pm 0.02$ & $0.02 \pm 0.002$ \\
JMY3010 & 30 & $0.13 \pm 0.02$ & $0.03 \pm 0.01$ \\
& 60 & $0.08 \pm 0.02$ & $0.12 \pm 0.02$ \\
\hline
\end{tabular}

Table 3

Maximum $\gamma$-decalactone and 3-hydroxy- $\gamma$-decalactone productivity in step-wise fed-batch cultures. Data are presented as the mean with the standard deviation of three independent experiments.

\begin{tabular}{lll}
\hline Strain & $\begin{array}{l}\gamma \text {-Decalactone } \\
\text { productivity step-wise } \\
\text { fed-batch }\left(\mathrm{g} \mathrm{L}^{-1} \mathrm{~h}^{-1}\right)\end{array}$ & $\begin{array}{l}\text { 3-Hydroxy- } \gamma \text {-decalactone } \\
\text { productivity step-wise } \\
\text { fed-batch } \\
\left(\mathrm{g} \mathrm{L}^{-1} \mathrm{~h}^{-1}\right)\end{array}$ \\
\hline W29 & $0.21 \pm 0.03$ & $0.05 \pm 0.01$ \\
MTYL40-2P & $0.10 \pm 0.02$ & $0.03 \pm 0.01$ \\
JMY3010 & $0.05 \pm 0.01$ & $0.02 \pm 0.01$ \\
\hline
\end{tabular}

Besides the differences observed in maximal aroma concentration obtained with the increase of $\mathrm{CO}$ concentration, the production rate was also changed. For W29, the increase in CO concentration leads to an increase in aroma production rate (a 4 -fold increase in maximum value, $444 \mathrm{mg} \mathrm{L}^{-1} \mathrm{~h}^{-1}$, after 10 and $24 \mathrm{~h}$ ), however a lag phase delay is observed at $60 \mathrm{~g} \mathrm{~L}^{-1} \mathrm{CO}$ when compared to $30 \mathrm{gL}^{-1}$ (Fig. 1). Also, a 2 -fold increase in the $\gamma$-decalactone consumption rate was observed with the CO increase $\left(-104 \mathrm{mg} \mathrm{L}^{-1} \mathrm{~h}^{-1}\right.$ $v s-211 \mathrm{mg} \mathrm{L}^{-1} \mathrm{~h}^{-1}$ ). For MTLY40-2P a lower initial (first $7 \mathrm{~h}$ ) production rate was observed compared to W29. However, at $30 \mathrm{CO}$ $\mathrm{g} \mathrm{L}^{-1}$ higher values of production rate were reached than for W29 (c.a. 2.5-fold). The increase of CO concentration for MTLY40-2P did not affect the maximum production rate attained but $\gamma$-decalactone consumption was observed. As JMY3010 has an additional copy of LIP2 gene, thus producing more lipase than the W29 and MTYL40$2 \mathrm{P}$, a fast initial aroma production occurred particularly for $30 \mathrm{~g} \mathrm{~L}^{-1}$ CO. For W29 and JMY3010 the increase of CO leads to an increase in the maximum production rate.

The lipase production was analyzed and higher activity was obtained with JMY3010 (2000 $\mathrm{UL}^{-1}$ to $\left.3500 \mathrm{UL}^{-1}\right)$ as expected. For W29 and MTLY40-2P lower activity was observed (1000 $\mathrm{UL}^{-1}$ and $840 \mathrm{UL}^{-1}$, respectively). These differences in extracellular lipase explain the delay observed in the $\gamma$-decalactone production for MTLY40-2P that was eliminated in JMY3010, overexpressing LIP2 gene. The existence of a lag phase particularly in MTLY40-2P in $\gamma$ decalactone production can be attributed to the time necessary for the synthesis of lipases, responsible for castor oil hydrolysis, and increasing ricinoleic acid availability (which is the substrate for the aroma synthesis) to the cells. This fact was also reported by Braga et al. [33] in which the addition of an extracellular enzyme during aroma production by $Y$. lipolytica W29 resulted in a reduction of the lag phase observed for $\gamma$-decalactone, since in these conditions the oil is hydrolyzed into ricinoleic acid earlier. In an industrial point of view, this process is not the most adequate since it is cost- and time-consuming. Thus, overexpressing Lip2 enzyme would bridge the gap of this problem by improving $\gamma$-decalactone production rate with no extra costs.

From Table 2 is clear that the highest aroma productivity was obtained for WT, since the highest aroma concentrations were achieved with this strain and MTLY40-2P, but due to the lag phase
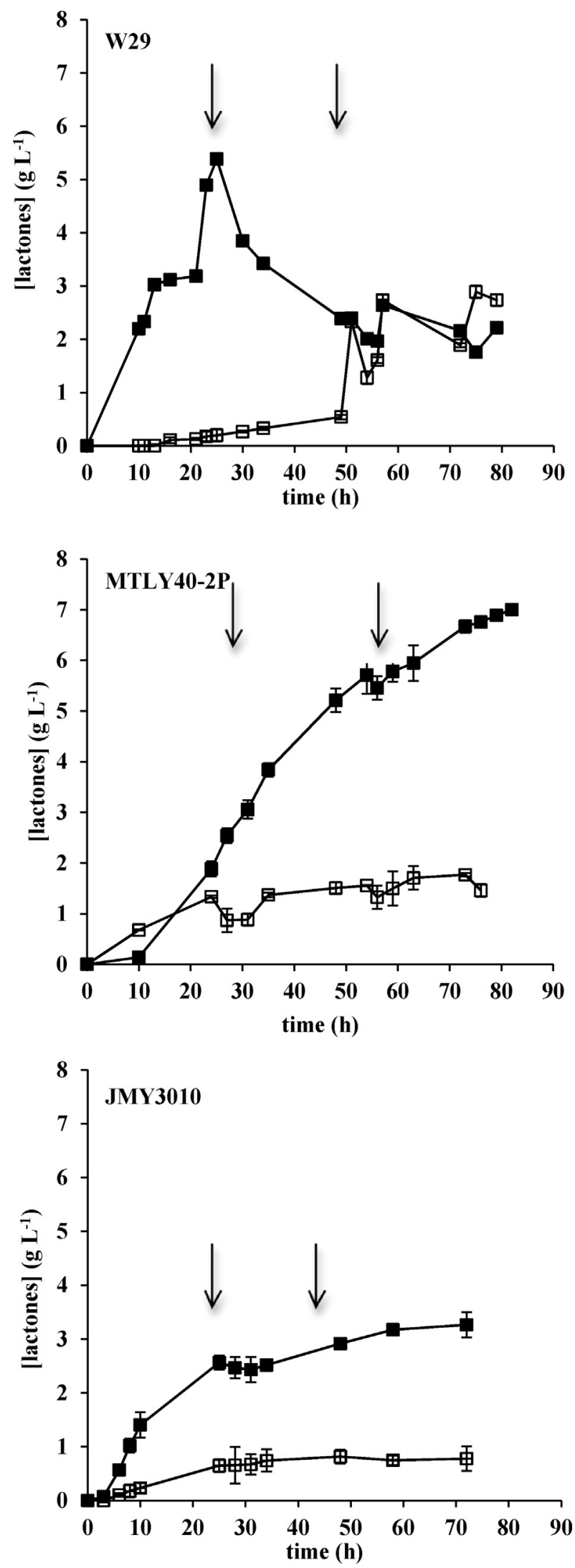

Fig. 2. $\gamma$-Decalactone ( $\square$ ) and 3-hydroxy- $\gamma$-decalactone $(\square)$ production in a stepwise fed-batch, after a batch phase with $60 \mathrm{~g} \mathrm{~L}^{-1}$ castor oil. The solid arrows indicate $60 \mathrm{~g} \mathrm{~L}^{-1}$ castor oil addition to the medium. Data are presented as mean with the standard deviation of three independent experiments. 
of this last, more time was needed to achieve the maximum concentration, leading to a lower global productivity. For JMY3010 a higher production rate was observed but the maximal aroma concentration obtained was lower, leading to lower productivities.

Concerning 3-hydroxy- $\gamma$-decalactone, the highest productivity was obtained with JMY3010 at higher CO concentration, contrarily to $\gamma$-decalactone, which showed lower productivity under those conditions.

\subsection{Step-wise fed-batch culture}

As a prospect to improve $\gamma$-decalactone productivity, a stepwise fed-batch strategy was attempted in which $60 \mathrm{~g} \mathrm{~L}^{-1}$ of castor oil was added in two pulses to the bioreactor (Fig. 2).

For W29 and JMY3010 no greater improvement in $\gamma$ decalactone production was achieved by using step-wise fed-batch culture, where only a 1.2-fold increase in aroma concentration was observed. On the other hand, a greater increase in aroma production was obtained for MTLY40-2P; in fact a 2-fold increase in $\gamma$-decalactone production was achieved leading to a maximum aroma concentration of $7 \mathrm{~g} \mathrm{~L}^{-1}$. Ambid et al. [38] studied the $\gamma$ decalactone production with Sporobolomyces odorus and methyl ricinoleate additions with $24 \mathrm{~h}$ gaps, and a 3 -fold improvement in aroma fed-batch production was obtained compared with batch mode, but the maximum aroma concentration reached was only $142.7 \mathrm{mg} \mathrm{L}^{-1}$.

Concerning the production of 3-hydroxy- $\gamma$-decalactone, in general, the concentrations obtained in fed-batch were similar with those obtained in batch for higher CO concentration (Fig. 1).

Tables 2 and 3 summarize the productivity values of $\gamma$ decalactone obtained with step-wise fed-batch and batch.

The highest $\gamma$-decalactone concentration was achieved with MTLY40-2P and around 2-fold improvement of maximum aroma concentration is observed in step-wise fed-batch mode compared to the batch culture, which have important impact in downstream processing cost savings.

Regarding 3-hydroxy- $\gamma$-decalactone productivity, higher values were obtained in batch mode since more time was needed to achieve the maximum hydroxyl-lactone concentration in fedbatch, leading to a lower global productivity.

\section{Conclusions}

Nowadays, industrial downstream process is one of the highest expensive step in any biotechnological setting. Therefore, is of the upmost importance the increase of studies aiming to achieve higher catalytic and capable strains from metabolic engineering pathways modification that would lead to an increase in accumulation of a desired product as well as reduction of other by products. In this study the effect of POX genotype and LIP2 overexpression on $\gamma$ decalactone production and reconsumption during castor oil use by $Y$. lipolytica was analyzed.

Our results show that using CO as substrate, mutant MTLY40-2P (disrupted in the genes POX2-5 and overexpressing Aox $2 \mathrm{p}$ ) prevented decrease of aroma at the end of the experiment and the production of hydroxylactone was minimized. Moreover, the overexpression of Lip2p gene increased the $\gamma$-decalactone production rate.

The $\gamma$-decalactone production by $Y$. lipolytica strains of different genotypes has been analyzed and castor oil concentration of $60 \mathrm{gL}^{-1}$ were shown to be the most adequate condition for $\gamma$ decalactone production in batch cultures. Although productivities in batch and step-wise fed-batch approaches where quite similar, a 2-fold improvement of maximum aroma concentration was obtained with MTLY40-2P in step-wise fed-batch mode compared to batch culture.
Considering the impact of castor oil hydrolysis to improve $\gamma$-decalactone production rate preliminary results highlight the importance to direct metabolic engineering in combining the POX level and LIP2 overexpression. We hypothesize that the glycerol repression is a key point, and that fine tuning of lipase expression and $\beta$-oxidation genes expression would probably lead to further improve $\gamma$-decalactone production.

\section{Acknowledgements}

The authors thank the Project 'Biolnd - Biotechnology and Bioengineering for improved Industrial and Agro-Food processes, REF. NORTE-07-0124-FEDER-000028' co-funded by the Programa Operacional Regional do Norte (ON.2 - O Novo Norte), QREN, FEDER and Fundação para a Ciência e a Tecnologia (FCT) (SFRH/BD/63701/2009 PhD grant to Adelaide Braga) for the financial support provided and FCT Strategic Project PEstOE/EQB/LA0023/2013.

\section{References}

[1] S. Okui, M. Uchiyama, M. Mizugaki, Metabolism of hydroxy fatty acids: II. Intermediates of the oxidative breakdown of ricinoleic acid by genus Candida, J. Biochem. 54 (1963) 536-540.

[2] A. Endrizzi-Joran, A.C. Awadé, J.-M. Belin, Presumptive involvement of methyl ricinoleate $\beta$-oxidation in the production of $\gamma$-decalactone by the yeast Pichia guilliermondii, FEMS Microbiol. Lett. 114 (1993) 153-160.

[3] I.L. Gatfield, M. Güntert, H. Sommer, P. Werkhoff, Some aspects of the microbiological production of flavour-active lactones with particular reference to $\gamma$-decalactone, Chem. Microbiol. Technol. Lebensm. 15 (1993) $165-170$.

[4] T. Haffner, R. Tressl, Biosynthesis of (R)-gamma-decanolactone in the yeast Sporobolomyces odorus, J. Agric. Food Chem. 44 (1996) 1218-1223.

[5] H.E. Spinnler, C. Giniès, J.A. Khan, E.N. Vulfson, Analysis of metabolic pathways by the growth of cells in the presence of organic solvents, Proc. Natl. Acad. Sci. U. S. A. 93 (1996) 3373-3376.

[6] G. Feron, L. Dufossé, E. Pierard, P. Bonnarme, J.-L. Le Quere, H.-E. Spinnler, Production, identification and toxicity of $\gamma$-decalactone and 4-hydroxydecanoic acid from Sporidiobolus spp, Appl. Environ. Microbiol. 62 (1996) 2826-2831.

[7] G. Feron, L. Dufossé, G. Mauvais, P. Bonnarme, H.E. Spinnler, Fatty acid accumulation in the yeast Sporidiobolus salmonicolor during batch production of $\gamma$-decalactone, FEMS Microbiol. Lett. 149 (1997) 17-24.

[8] A. Endrizzi-Joran, Ph.D. thesis, Université de Bourgogne, Dijon, France, 1994

[9] Y. Waché, C. Laroche, K. Bergmark, C. Møller-Andersen, M. Aguedo, M.-T. Le Dall, H. Wang, J.-M. Nicaud, J.-M. Beli, Involvement of acyl-CoA oxidase isozymes in biotransformation of methyl ricinoleate into $\gamma$-decalactone by Yarrowia lipolytica, Appl. Environ. Microbiol. 66 (2000) 1233-1236.

[10] Y. Waché, Y. Pagot, J.-M. Nicaud, J.-M. Belin, Acyl-CoA oxidase, a key step for lactone production by Yarrowia lipolytica, J. Mol. Catal. B: Enzym. 5 (1998) $165-169$.

[11] H. Wang, M.T. Le Dall, Y. Wache, C. Laroche, J.M. Belin, J.M. Nicaud, Cloning, sequencing and characterization of five genes coding for Acyl-CoA oxidase isozymes in the yeast Yarrowia lipolytica, Cell Biochem. Biophys. 31 (1999) $103-112$.

[12] H.J. Wang, M.-T. Le Dall, Y. Waché, J--M. Belin, C. Gaillardin, J.-M. Nicaud, Evaluation of Acyl-CoA oxidase (Aox) isozymes function in the n-alkanes-assimilating yeast Yarrowia lipolytica, J. Bacteriol. 181 (1999) 5140-5148.

[13] Y. Luo, H. Wang, K. Gopolan, D. Srivastava, J.-M. Nicaud, T. Chardot, Purification and characterisation of the recombinant form of acyl-CoA oxidase 3 from the yeast Y. lipolytica, Arch. Biochem. Biophys. 384 (2000) 1-8.

[14] Y. Luo, J.M. Nicaud, P. Van Veldhoven, T. Chardot, The acyl-CoA oxidase from the yeast Y. lipolytica: characterisation of Aox2p, Arch. Biochem. Biophys. 407 (2002) 32-38.

[15] E.E. García, Aspects de la dégradation de substances hydrophobes en composés d'arômes par la levure Yarrowia lipolytica (Ph.D. thesis), Université de Bourgogne, Dijon, France, 2008.

[16] A. Groguenin, Y. Waché, E.E. García, M. Aguedo, F. Husson, M.T. LeDall, J.-M. Nicaud, J.-M. Belin, Genetic engineering of the $\beta$-oxidation pathway in the yeast Yarrowia lipolytica to increase the production of aroma compounds, J. Mol. Catal. B: Enzym. 28 (2004) 75-79.

[17] Y. Guo, C. Feng, H. Song, Z. Wang, Q. Ren, R. Wang, Effect of POX3 gene disruption using self-cloning CRF1 cassette in Yarrowia lipolytica on the $\gamma$-decalactone production, World J. Microbiol. Biotechnol. 27 (2011) 2807-2812.

[18] Y. Guo, H. Song, Z. Wang, Y. Ding, Expression of POX2 gene and disruption of $P O X 3$ genes in the industrial Yarrowia lipolytica on the $\gamma$-decalactone production, World J. Microbiol. Biotechnol. 167 (2011) 246-252. 
[19] Y. Waché, M. Aguedo, A. Choquet, I.L. Gatfield, J.-M. Nicaud, J.-M. Belin, Role of $\beta$-oxidation enzymes in $\gamma$-decalactone production by the yeast Yarrowia lipolytica, Appl. Environ. Microbiol. 67 (2001) 5700-5704.

[20] Y. Waché, M. Aguedo, J.-M. Nicaud, J.-M. Belin, Catabolism of hydroxyacids and biotechnological production of lactones by Yarrowia lipolytica, Appl. Microbiol. Biotechnol. 61 (2003) 393-404.

[21] A. Braga, I. Belo, Production of $\gamma$-decalactone by Yarrowia lipolytica: insights into experimental conditions and operation mode optimization, J. Chem. Technol. Biotechnol. (2014), http://dx.doi.org/10.1002/jctb.4349

[22] N. Gomes, J.A. Teixeira, I. Belo, Fed-batch versus batch cultures of Yarrowia lipolytica for $\gamma$-decalactone production from methyl ricinoleate, Biotechnol. Lett. 34 (2012) 649-654.

[23] M. Aguedo, N. Gomes, E.E. García, Y. Waché, M. Mota, J.A. Teixeira, I. Belo, $\gamma$-Decalactone production by Yarrowia lipolytica under increased $\mathrm{O}_{2}$ transfer rates, Biotechnol. Lett. 27 (2005) 1617-1621.

[24] N. Gomes, M. Aguedo, J. Teixeira, I. Belo, Oxygen transfer rate in a biphasic medium: influence on the biotransformation of methyl ricinoleate into $\gamma$-decalactone by the yeast Yarrowia lipolytica, Biochem. Eng. J. 35 (2007) 380-386.

[25] Y. Pagot, A. Le Clainche, J.-M. Nicaud, Y. Waché, J.-M. Belin, Peroxisomal $\beta$-oxidation activities and $\gamma$-decalactone production by the yeast Yarrowia lipolytica, Appl. Microbiol. Biotechnol. 49 (1998) 295-300.

[26] C. Blin-Perrin, D. Molle, L. Dufossé, J.-L. Le-Quere, C. Viel, G. Mauvais, G. Feron, Metabolism of ricinoleic acid into $\gamma$-decalactone: $\beta$-oxidation and long chain acyl intermediates of ricinoleic acid in the genus Sporidiobolus sp, FEMS Microbiol. Lett. 188 (2000) 69-74.

[27] V.I. Titorenko, J.M. Nicaud, H. Wang, C. Honey, R.A. Rachubinski, Acyl-CoA oxidase is imported as a heteropentameric, cofactor-containing complex into peroxisomes of Yarrowia lipolytica, J. Cell Biol. 156 (2002) 481-494.
[28] A. Braga, N. Gomes, J.A. Teixeira, I. Belo, Impact of lipase-mediated hydrolysis of castor oil on $\gamma$-decalactone production by Yarrowia lipolytica, J. Am. Oil Chem. Soc. 90 (2013) 1131-1137.

[29] G. Barth, C. Gaillardin, Physiology and genetics of the dimorphic fungus Yarrowia lipolytica, FEMS Microbiol. Rev. 19 (1997) 219-237.

[30] J.M. Nicaud, C. Madzak, P. van den Broek, C. Gysler, P. Duboc, P. Neiderberger, C. Gaillardin, Protein expression and secretion in the yeast Yarrowia lipolytica, FEMS Yeast Res. 2 (2002) 371-379

[31] N. Gomes, J.A. Teixeira, I. Belo, The use of methyl ricinoleate in lactone production by Yarrowia lipolytica: aspects of bioprocess operation that influence the overall performance, Biocatal. Biotransform. 28 (2010) 227-234

[32] N. Gomes, C. Gonçalves, M. García-Román, J.A. Teixeira, I. Belo, Optimization of a colorimetric assay for yeast lipase activity in complex systems, Anal. Methods 3 (2011) 1008-1013.

[33] A. Braga, N. Gomes, J.A. Teixeira, I. Belo, Lipase induction in Yarrowia lipolytica for castor oil hydrolysis and its effect on $\gamma$-decalactone production, J. Am. Oil Chem. Soc. 89 (2012) 1041-1047.

[34] J.P. Mather, P.E. Roberts, Introduction to Cell and Tissue Culture: Theory and Technique, Plenum Press, New York, 1998.

[35] J. An, Y.-C. Joo, D.-K. Oh, New biotransformation process for the production of the fragrance $\gamma$-dodecalactone from 10-hydroxystearate by permeabilized Waltomyces lipofer cells, Appl. Environ. Microbiol. 79 (2013) 2636-2641.

[36] M. Alchihab, J.-M. Aldric, M. Aguedo, J. Destain, J.-P. Wathelet, P. Thonart, The use of Macronet resins to recover $\gamma$-decalactone produced by Rhodotorula aurantiaca from the culture broth, J. Ind. Microbiol. Biotechnol. 37 (2010) $167-172$.

[37] Y. Waché, M. Aguedo, M.T. Le-Dall, J.M. Nicaud, J.M. Belin, Optimization of Yarrowia lipolytica's $\beta$-oxidation pathway for $\gamma$-decalactone production, J. Mol. Catal. B: Enzym. 19 (2002) 347-351

[38] C. Ambid, S. Carle, G. De Billerbeck, Process for producing and extracting aromatic compounds. US Patent 6518050B1, 2003. 